\title{
UNIT CHARACTERS
}

\section{Reality of Their Existence is Fundamental to Study of Evolution, But Has Never \\ Been Proved-Independent Variability of Parts and Independent Transmissibility of Variations Open to Question}

\author{
S. J. Holmes
}

Associate Professor of Zoology, University of California, Berkeley, Cal.

T

HE doctrine of unit characters is one that has figured largely in speculations on heredity and evolution from the time of Darwin to the present. According to this doctrine an organism is a sort of mosaic of parts each of which is dependent for its development upon some kind of discrete entity in the germ cell.

The germ cell is therefore considered a complex of organic units more or less independent of one another in their activities and transmission.

The unit character hypothesis is founded on (1) the assumed independent variability of the parts of an organism, and (2) the assumption that characters are capable of independent transmission. Independent variability was appealed to by Darwin in support of his hypothetical gemmules, by De Vries in his Intracellular Pangenesis, and especially by Weismann who has adduced a formidable array of facts in support of this doctrine upon which he founds much of his argument for the complex organization of the germ plasm.

"There are human families," says Weismann, "in which individuals occur repeatedly, and through several generations, who have a white lock of hair, in a particular spot, on an otherwise darkhaired head. This cannot be referred to external influences, it must depend on a difference in the ger $m$, on one, too, which does not affect the whole body, not even all the hairs of the body, but only those of a particular spot on the surface of the head. It is a matter of indifference whether the white coloring of the hair-tuft is produced by an abnormal constitution of the matrix of the hair, or by other histological elements of the skin, as of the bloodvessels or nerves. It can only depend ultimately on a divergently constituted part of the germplasm, which can only affect this one spot on the head, and alter it, if it is itself different from what is usual. On this account I call it the determinant of the relevant skin-spot and hair-group."

"There must be as many of these (determinants) as there are regions in the fully-formed organism capable of independent and transmissible variation, including all the stages of development."

Weismann has no quarrel with epigenesis ${ }^{2}$ as a theoretic possibility. The complexity of the germ plasm is to be measured by the amount of independent variability occuring in the parts of the organism. How great this amount is, how many parts are capable of undergoing heritable changes independently of the others is a question to be answered only through extensive observation, but one nevertheless capable, at least theoretically, of being answered.

\section{WEISMANN'S ARGUMENT}

Weismann argues with great plausibility that the number of independently

' Read before a joint meeting of the zoological section, American Association for the Advancement of Science, and the American Genetic Association, at Stanford University, August 4, 1915.

2 Older naturalists imagined that a minute but complete embryo must be preformed and incased in either the egg or the sperm. In $1759 \mathrm{C}$. F. Wolff enunciated the doctrine of epigenesis which, modified by later discoveries, is still accepted by the world of science. As at present understood, it declares that there is no pre-existence of an organism as such, but that the embryo is a new thing created as the result of the union of egg and sperm cells.-THE EDITOR. 
heritable variations presented by organisms must be great, because it would be impossible to have complex organs evolving simultancously, as they obviously have done, unless the improvements in the one did not modify or interfere with improvements in the others. If every variation making toward the perfection of the eye were tied up with a variation in the ear, the organs of digestion, and the structure of the limbs, it seems inevitable that there would be so much interference with one another's progress that any progressive evolution of a number of complex organ systems would be practically impossible. Variations accumulating toward the perfection of any one organ, argues Weismann, would in all probability, work toward the undoing of various other organs. Independent variability of parts must, therefore be assumed in order to make the evolution of a complex organization possible through variation and natural selection.

There is much apparent force in this argument for the conception of the organism as a mosaic product. Its real weight is difficult to estimate, plausible as it may appear, because we know so little of the possibilities of organismal variability. However the assumption of any particular kind of variability may increase or lighten the task of explaining how evolution takes place, it is obviously our first duty to inquire whether or not organisms actually vary in the way alleged. Since so much has been built upon the doctrine of independent variability of parts, the the burden of proof may fairly be held to rest with those who espouse this theory.

Let us therefore consider some of the alleged instances of independent variation. Take the classical case cited by Wcismann, of the small pit in the ear which ran through several successive generations. As this is an inherited character, the germ plasm of the person transmitting it must be slightly different from that of a person without this defect. But does it follow that "it can only depend ultimately on a divergently constituted part of the germplasm, which can only affect this one spot on the head, and alter it, if it is itself different from what is usual?"

If variations such as this could come and go, leaving the rest of the organism unmodified, we should be logically led, I believe, to adopt Weismann's conclusion that these variations depend on independent carriers of some sort in the germplasm. Weismann's reasoning is good, so far as his doctrine of determinants goes, if we grant his fundamental assumption. If a small pit in the ear were absolutely the sole hereditary difference between two human beings we might be forced to consider it as a unit character depending on a special determinant, determiner, or other germinal unit or entity. But do we know that the facts are as Weismann assumes?

\section{STUDIES NOT DEEP ENOUGH}

I am quite sure that these people with a pit in the ear have never been very critically studied to find whether or not this small character may not be a mere expression of more general differences in constitution. It might very well be that this pit is simply a relatively obvious manifestation of a very slight difference which affects the organism as a whole. The same may be true of the white lock of hair and numerous other characters which appear to vary independently of the rest of the body.

The now neglected study of correlated variability has revealed numerous cases in which what appear as single variations have far-reaching connections. Supernumerary horns in sheep are said by Youatt to go along with great "length and coarseness of the fleece." In mammals in general there is a strong tendency for variation to affect simultaneously hair, teeth and hoofs or claws. Darwin points out that the white star in the forehead of horses is generally correlated with white feet, and that in "white rabbits and cattle, dark marks often co-exist on the tips of the ears and on the feet." Polydactylism, as is well known, tends to affect both hands and feet. How are we to interpret these correlations? If hands and feet vary together do the intervening parts of the skeleton re- 
main unaffected? If tip of ears and hind feet show parallel variations in color does it not suggest that we are here dealing with a sort of outcropping of a color variation which is really present, but less conspicuously expressed in other parts of the skin? That bodily changes of a general nature may manifest themselves to ordinary observation in one or at least a very few characteristics is clearly shown in the effects of many diseases. Infectious diseases may have their characteristic symptoms in certain form-changes while leaving the rest of the body apparently unaffected. Hutchinson's teeth ${ }^{3}$ in children for instance are the index of a general bodily disease which may have no other very obvious sign.

Introduce some toxin of disease into the body and you produce certain specific characters. Introduce a change affecting all the cells and certain parts only will reveal the fact by noticeable modifications. The appearance of independent variability of parts may thus result from variations that are in reality organismal in their extent. Not only have so-called particular variations not been studied sufficiently to establish the fact that they are really independent, but numerous cases are known in which variations which to casual observations would seem to affect but a single part, are nevertheless correlated with minor changes of wide extent. We contend therefore that the alleged independent variability of parts upon which Darwin, De Vries, Weismann and others have based so much of their argument for the existence of discrete germinal units rests upon an insecure foundation.

\section{INDEPENDENT TRANSMISSION}

The question of the independent transmission of characters may be dealt with more briefly. Owing to the independent way in which so-called characters such as tallness and dwarfness, flower color, characters of seed coat and various other parts of peas may be separated and combined almost at will according to the fancy of the breeder it has become customary to look upon these characters as discrete entities borne by discrete elements in the germ cells, and to consider the organism as a mosaic of independently heritable parts. From this viewpoint organisms may be likened to brick buildings in which the bricks may be taken out and replaced by others without materially affecting, except secondarily, the bricks which make up the rest of the structure. But although the facts of Mendelian inheritance are usually interpreted according to the mosaic conception, they do not I believe necessitate the adoption of this standpoint. When the Anlage of a green pea is separated from that of a yellow one we are not compelled to assume that something in the germ cell that stands for just greenness is separated from something that is the representative of mere yellowness. We need assume only that what are separated are the Anlagen of organisms as wholes possessing the characteristics in question. In other words green and yellow represent organismal variations; expressed in Weismannian terms, green and yellow depend not on determinants, but upon ids, the hereditary bases of whole organisms.

The logical consequence of this standpoint we have presented is that all Mendelian characters are really general and constitutional, however they may appear to be limited to a particular feature of the organism. Many Mendelian characters are quite patently constitutional while others are apparently very limited in their extent like pea and rose comb in poultry. Attention has been so taken up with characters per se that I doubt if much careful scrutiny has been given to the possible correlations of characters in other parts of the body. Has anyone for instance very carefully looked for any more general attributes which may be associated with pea or rose comb, or with the smooth and wrinkled coats of peas? Correlations may be difficult to detect, not only for the reasons previously mentioned, but because the

\footnotetext{
${ }^{3}$ Hutchinson's teeth are a form of incisor teeth indicative of hereditary syphilis.

4 Anlage is a German term much used by genetists to denote the hypothetical something in the germ-cells which determines the nature of a given part of the adult organism.-THE EDIToR.
} 
associated characters may not improbably have different relations of dominance or recessiveness from that of their more obvious correlates. The question which we have raised can, at least theoretically, be decided by observation and experiment. However it is decided will make little practical difference with most of the problems that confront the investigator in genetics. But there are certain problems of genetics, I suspect, in regard to which it will be found to have an important bearing, although its chief importance is in the way it influences our views on certain fundamental problems of ontogeny and evolution. I can here indicate but a few cases in point:

\section{BEARING ON EVOLUTION}

Since I have come to see more clearly the implications of the question I have discussed, I have been surprised to find how many of the difficulties urged against the theory of natural selection disappear when we consider variations as organismal instead of limited primarily to particular parts. Most discussions, I find, consider evolutionary problems from the standpoint of the doctrine of unit characters. How common it is to find speculations as to how this or the other character could have been developed through natural selection, as if each part were somehow separately improved by a series of fortunate survivals. If each character is considered as the summation of a series of variations which primarily concern that character alone, and if the nature of the variations that are integrated is determined by natural selection, we should expect most attributes of an organism to be of a useful kind. If, on the other hand, variations of any one part involve variations throughout the organism, then the preservation of favorable variations in any one organ would of necessity entail changes in other organs which for the most part would probably have no relation to utility. On this view a considerable ingredient of non-adoptive characters would naturally be expected, and it is probable that, through correlation, parts might be evolved to a considerable degree of complexity without having any important use in the life of the organism, provided they did not become positively dangerous to their possessors. Much of the evidence adduced for or thogenesis is what we should expect to find if evolution occurred through the selection of organismal variations. Much of the difficulty about the beginnings of structures and their development up to the point where they acquire selective value would, I believe, also be removed. The wonder is not so much that selection should produce a large amount of what Haeckel would call dysteleological structures, but that it is able to produce (if we grant that it does produce) so much that is so nicely coadapted, and especially that it is able to carry on the simultaneous elaboration and perfection of numerous separate systems of organs.

In these days of attack upon evolutionary problems through direct observation and experiment, I hope I may be pardoned for presenting anything so atavistic as an academic discussion of the method of evolution. But even with our present accumulation of facts bearing on this much discussed problem there is still something to be gained by reflection, and if our reflection suggests new things to look for it will assuredly not be in vain.

\section{How to Make a Eugenical Family Study.}

Detailed suggestions to genealogists and others who want to study their ancestry, are contained in Bulletin No. 13 of the Eugenics Record Office, Cold Spring Harbor, Long Island, N. Y., which has just been issued under the title, "How to Make a Eugenical Family Study," and which will be sent to serious inquirers, upon request. It explains and fully illustrates the proper procedure, and also points out at some length the value of a knowledge of the eugenic quality of one's ancestry. Many people have been deterred from studying their family trees biologically, because they did not know how to begin; this bulletin will prove of great help to them. 